\title{
Mosaic Tetrasomy of 9p24.3q21.11 postnatally identified in an infant born with multiple congenital malformations: a case report
}

Irene Plaza Pinto ${ }^{1,2^{*}}$, Lysa Bernardes Minasi ${ }^{2,3}$, Raphael Steckelberg ${ }^{4,5}$, Claudio Carlos da Silva ${ }^{1,2,3,6,7}$ and Aparecido Divino da Cruz ${ }^{1,2,3,6}$

\begin{abstract}
Background: Supernumerary Marker Chromosomes consist in structurally abnormal chromosomes, considered as an extra chromosome in which around $70 \%$ occur as a de novo event and about 30\% of the cases are mosaic. Tetrasomy $9 p$ is a rare chromosomal abnormality described as the presence of a supernumerary isochromosome $9 p$. Clinical features of tetrasomy 9p include a variety of physical and developmental abnormalities.

Case presentation: Herein, we reported a postnatal case of a newborn who died in early infancy with multiple congenital malformations due to a mosaic de novo tetrasomy 9p detected by Chromosomal Microarray Analysis. Conventional cytogenetics analysis of the proband was 47,XY,+mar[45]/46,XY[5]. The parental karyotypes presented no visible numerical or structural alterations. Microarray Analysis of the proband revealed that the marker chromosome corresponded to a mosaic de novo gain at 9p24.3q21.11.

Conclusions: Chromosomal Microarray Analysis was helpful to identify the origin of the supernumerary marker chromosome and it was a powerful tool to carry out genetic diagnostic, guiding the medical diagnosis. Furthermore, the CMA allowed observing at the first time in Central Brazil the tetrasomy $9 p$ and partial tetrasomy $9 q$ in mosaic, encompassing a large duplicated region with several morbid genes, in an infant with multiple congenital malformations.
\end{abstract}

Keywords: SMC, Chromosome 9, Congenital disorders, Genetics, CMA

\section{Background}

Supernumerary Marker Chromosomes (SMC) are structurally abnormal chromosomes whose origin cannot to be adequately established by $\mathrm{G}$ banding karyotyping $[1,2]$. In general, SMC are seen as an extra chromosome in metaphase spreads with an incidence rate of $0.43 / 1000$ in postnatal cases and about $1 / 1000$ in prenatal testing.

* Correspondence: iplazapinto@gmail.com

${ }^{1}$ Biotechnology and Biodiversity PhD Program, Federal University of Goias, Rede Centro Oeste de Pós-Graduação de Pesquisa e Inovação, Rua 235, n. 40, Setor Leste Universitário, Goiânia, GO 74605-050, Brazil

${ }^{2}$ Replicon Research Group, Department of Biology, Pontifical Catholic University of Goias, Rua 235, n. 40, Setor Leste Universitário, Goiânia, GO 74605-050, Brazil

Full list of author information is available at the end of the article
Approximately $70 \%$ of SMC occur de novo and about $30 \%$ of the cases are mosaic $[3,4]$.

Tetrasomy $9 \mathrm{p}$ is a rare chromosomal abnormality described as the presence of a supernumerary isochromosome 9p, initially found as a SMC. Further investigation of the SMC commonly shows involvement of the entire $9 p$, or the entire $9 p$ with part of the heterochromatic region of $9 q$, or yet the entire $9 p$ with heterochromatic region of $9 \mathrm{q}$, and part of the euchromatic material of $9 \mathrm{q}$ [5, 6]. Moreover, around 30\% of known cases of tetrasomy $9 \mathrm{p}$ exhibits chromosome mosaicism. Both constitutive and mosaic SMC of chromosome 9 comprises a clinically noticeable syndrome $[3,7,8]$.

Clinical phenotype of tetrasomy $9 \mathrm{p}$ includes a variety of physical and developmental abnormalities. Commonly,

(c) The Author(s). 2018 Open Access This article is distributed under the terms of the Creative Commons Attribution 4.0 International License (http://creativecommons.org/licenses/by/4.0/), which permits unrestricted use, distribution, and reproduction in any medium, provided you give appropriate credit to the original author(s) and the source, provide a link to the Creative Commons license, and indicate if changes were made. The Creative Commons Public Domain Dedication waiver (http://creativecommons.org/publicdomain/zero/1.0/) applies to the data made available in this article, unless otherwise stated. 
patients have distinctive facial appearances with hypertelorism, cleft lip or palate, ear anomalies, and micrognathia $[3,9]$. In addition, recurrent clinical features include developmental delay, central nervous system anomaly, limb defects, postnatal growth failure, congenital heart disease, renal anomalies, and short neck with excess nuchal skin [8].

Herein, we report a postnatal case of a newborn who had multiple congenital malformations due to a mosaic de novo tetrasomy of $9 \mathrm{p}$ and partial tetrasomy of $9 \mathrm{q}$ detected by Chromosomal Microarray Analysis (CMA).

\section{Case presentation}

The proband was a preterm newborn boy, the first child of non-consanguineous parents, born at 31 weeks gestation to a 44-year old father and a 43-year old mother by cesarean section. At birth, the child weighed 1,480 g, measured $44 \mathrm{~cm}$ in crown-to-heel length, and exhibited multiple congenital anomalies. The newborn was transferred to the Intensive Care Units (ICU) immediately after birth. His general health condition deteriorated progressively, leading to his death at 105th days after birth. The newborn had brain malformation, including ventriculomegaly and corpus callosum dysgenesis, cleft lip and palate, retrognathism, hypertelorism, clenched hands with overlapping fingers, and hypotonia. Additionally, he revealed mild heart septal hypertrophy, ambiguous genitalia, enlarged kidneys without corticomedullary differentiation, and gallbladder with tiny cystic formations (Fig. 1). His mother had three miscarriages from previous marriages and one miscarriage with her current husband. The remaining of his family history was otherwise unremarkable.

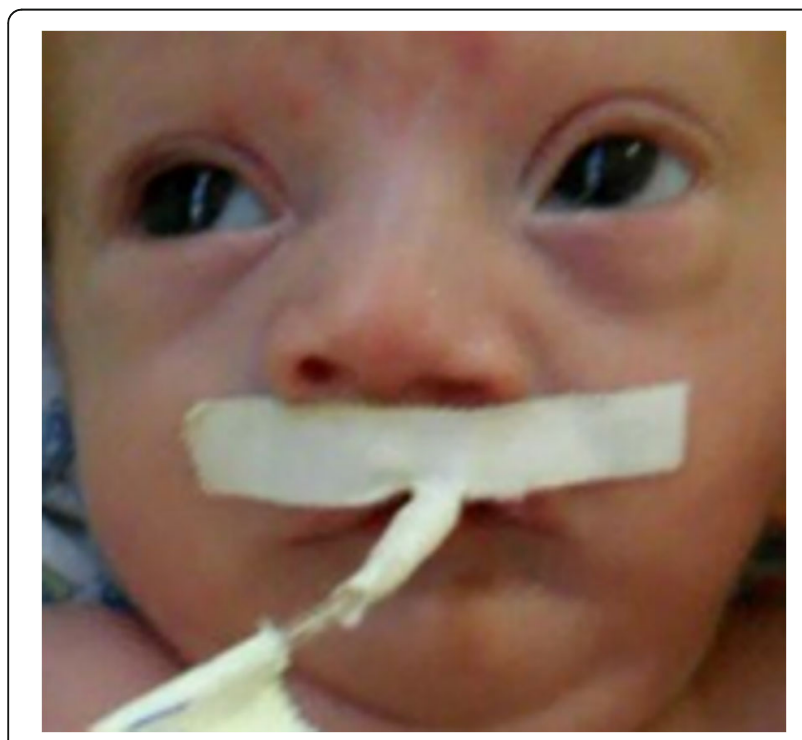

Fig. 1 Dismorphological facial features of newborn with multiple congenital malformations from Central Brazil
Both parents signed a written informed consent and the mother signed as the legal representative for the child. Peripheral blood was obtained to isolate genomic DNA for CMA using Qiagen QIAamp ${ }^{\circ}$ DNA Mini kit (Hilden, Germany). Karyotyping was performed in a private laboratory through conventional cell culture, harvesting, and GTG banding with a > 550 bands resolution following standard procedures [10]. Chromosome analyses were done using Zeiss Axio Scope (Jena, Germany) and the software IKAROS ${ }^{\circ}$ (Metasystems Corporation, Altlussheim, Germany). All laboratory procedures were carried out following international standardized protocols and consensual criteria of quality.

The CMA was carried out on proband and his biological parents using the GeneChip ${ }^{\circ}$ CytoScanHD ${ }^{\mathrm{m}}$ (Affymetrix, Santa Clara, USA) following the manufacturer's recommendations without modifications. Chromosomal analyses were done using the Chromosome Analysis Suite $\left(\mathrm{ChAS}^{\circ}\right)$ software (Affymetrix, Santa Clara, USA) and the CNVs found in the patient were analyzed in comparison with public databases, including Database of Genomic Variants (DGV), Database of Chromosomal Imbalance and Phenotype in Humans using Ensemble Resources (DECIPHER), and CytoScanHD ${ }^{\text {ma }}$ Array Database. Furthermore, $\mathrm{CNVs}$ were classified according to their nature, based on $[11,12]$.

The proband showed a male karyotype with a large submetacentric SMC in $90 \%$ of the analyzed metaphases after counting 50 metaphase spreads. His karyotype was $47, \mathrm{XY},+\operatorname{mar}[45] / 46, \mathrm{XY}[5]$, suggesting $10 \%$ mosaicism. The parental karyotypes and CMA results had no visible numerical or structural alterations. The proband's CMA revealed the marker chromosome corresponded to a de novo $70.77 \mathrm{Mb}$ gain at arr[GRCh37] 9p24.3q21.11 $(203,861$ 70,974,662) $\times 4[0.3] \mathrm{dn}$ with $30 \%$ mosaicism, encompassing 286 genes, including 152 OMIM morbid genes (Fig. 2).

\section{Discussion and conclusions}

Chromosomal alterations associated with a spectrum of multiple congenital anomalies are most frequently numerical and are identified in $0.3-1 \%$ of newborns $[13,14]$. Partial tetrasomy 9 is not yet a well recognizable clinical syndrome due to the limited number of postnatal cases described to date. Moreover, patients with partial tetrasomy 9 have variable phenotypes depending on the size and position of the duplicated region and the degree of mosaicism $[6-8,15]$.

Here we reported a case of a boy who died postneonataly in early infancy whose karyotype indicated an additional SMC which origin could not be determined by GTG-banding. Microarray analysis showed 47,XY,+mar[45]/46,XY[5].arr [GRCh37] 9p24.3q21.11(203,861_70,974,662)×4[0.3] dn. Copy Number Variations (CNVs) within the region of gain 


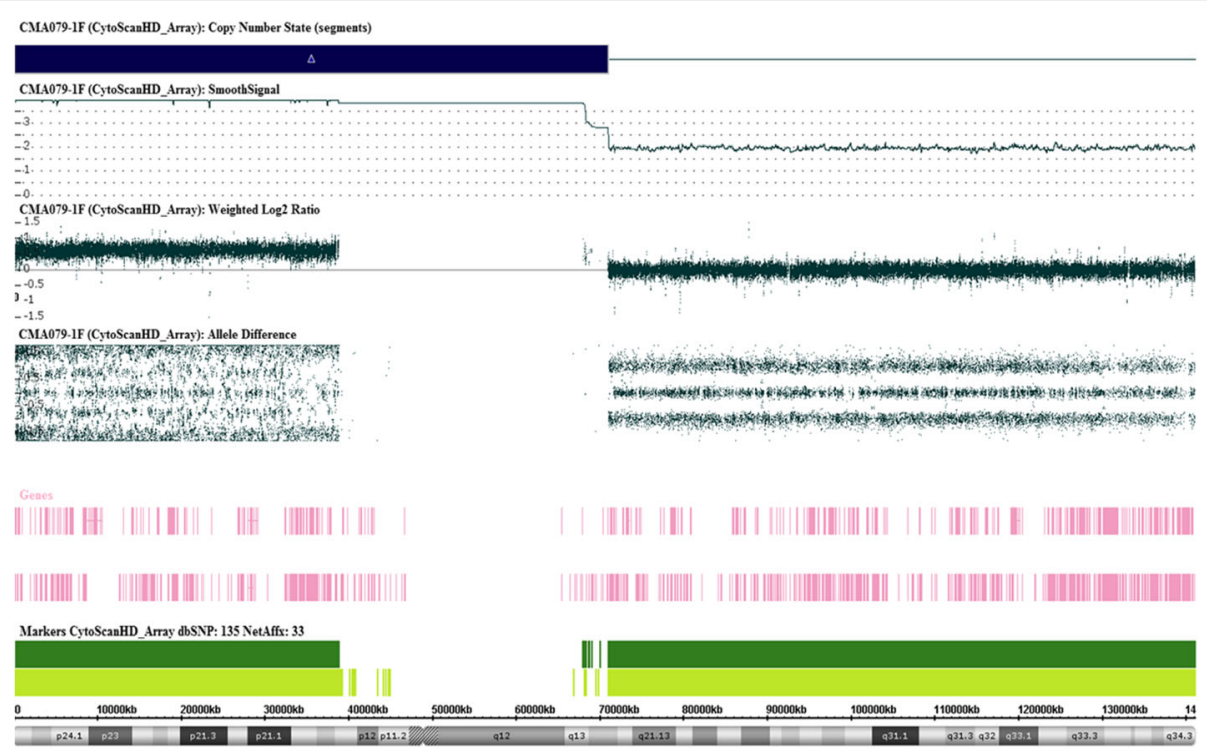

Fig. $2 \mathrm{ChAS}^{\circledast}$ (Affymetrix, USA) interface indicating the results of Chromosomal Microarray Analysis showing the derivative chromosome 9 responsible for tetrasomy $9 p$ extended distally to 9q21.11

indicated tetrasomy, revealing full tetrasomy $9 p$ and partial tetrasomy 9q, including the proximal euchromatic region of the long arm in a mosaic state. Parental CMA were uneventful.

According to [4], about of $40 \%$ of all SMCs are derived from non-acrocentric autosomes and the risk of an abnormal phenotype is approximately $28 \%$. Mosaic tetrasomy of $9 p$ most commonly arises as a de novo chromosomal rearrangement resulting from an early sporadic error in embryonic development. Thus, the risk of recurrence is relatively low and this has important implications in genetic counseling for the family [16]. Furthermore, it is important to emphasize the mother history of miscarriage because either a cryptic translocation or some aberrant chromosomal constitution restricted to the mother's gonads, most likely as a gonadal mosaicism, could be responsible for her failure to conceive health offspring. However, the family refused to undergo genetic counseling and refused any additional genetic testing.

Tetrasomy $9 \mathrm{p}$ is a rare disorder firstly described by [17]. Up to now, at least 34 postnatal cases have been previously reported in medical literature, varying greatly in chromosomal range and phenotype severity. Although the affected population is small, males seemed to be slightly more affected than females [5]. The clinical severity of tetrasomy $9 p$ varies from neonatal death to mild developmental delay and minor anomalies $[9,18,19]$. Furthermore, when the tetrasomic segment extend to $9 q 22-9 q 32$ it is common to observe intrauterine growth retardation, skeletal anomalies, cleft lip/palate, and heart defects [15].
According to some authors, three different types of supernumerary isochromosome $9 \mathrm{p}$ have been described so far. There are tetrasomies containing exclusively the entire $9 p$, some includes the entire $9 p$ and a small proportion of the heterochromatic region of $9 q$, and yet some harbors the entire $9 p$ and a large portion of $9 q$ extending to $9 \mathrm{q} 21$, including both heterochromatic and euchromatic regions of $9 q[3,5,6]$. The tetrasomy was categorized as the third type of SMC involving chromosome 9, with breakpoints at 9q21.11 and isochromosome 9p, justifying the severity of symptoms in the studied proband.

There is a positive correlation between degree of mosaicism and the severity of the phenotype in infants having tetrasomy 9p. However, the breakpoint of 9q extended distally to 9q21.11, which encompasses a large duplicated region with several OMIM morbid genes. This finding supports the claim the nature of the involved genes was more crucial than the level of mosaicism in defining phenotype's severity in our proband.

The CMA was helpful to identify the origin of the SMC in the proband born to parents with normal karyotypes. In addition, it was an effective method to identify the tetrasomy $9 \mathrm{p}$ and partial tetrasomy $9 \mathrm{q}$ in mosaic in an infant with multiple congenital malformations for the first time in Central Brazil. Rare and complex phenotypes must always be investigated to define subsets and allow the phenotype/genotype correlation. Furthermore, it was recommended to the family to undergo a non-directive genetic counseling to help understanding the familial implications of genetic contribution to disease and the chance of recurrence. 


\section{Abbreviations}

ChAS: Chromosome Analysis Suite; CMA: Chromosomal Microarray Analysis; CNVs: Copy Number Variations; DECIPHER: Database of Chromosomal Imbalance and Phenotype in Humans using Ensemble Resources; DGV: Database of Genomic Variants; ICU: Intensive Care Units; OMIM: Online Mendenlian Inheritance in Man; SMC: Supernumerary Marker Chromosomes; SNP: Single Nucleotide Polymorphism

\section{Acknowledgments}

The authors wish to thank Dr. Rinaldo W. Pereira and the Rede ExeGenes for supporting the betterment of genetic diagnosis in Central Brazil. We are also grateful for Mr. Sean M. Quail's contribution for proofreading the manuscript and assistance with the English language. This work was sponsored by a grant from CNPq (Edital 031/564465/2010-10) and FAPEG (2011.6002.19.1847.1134-03). IPP holds a scholarship from CAPES/UFG.

\section{Availability of data and materials}

All data generated or analyzed during this study are included in this published article.

\section{Authors' contributions}

IPP, LBM, RS, CCS and ADC have made substantial contributions to conception and design the experiment. RS was the patient's attending physician. IPP performed CMA experiments. IPP, LBM, CCS, and ADC analyzed the data. IPP, ADC and LBM wrote the paper. All authors read and approved the final manuscript.

\section{Ethics approval and consent to participate}

This study was approved by the Pontifícia Universidade Católica de Goiás ethics approval (CAAE 0051.0.168.000-11) and the family (parents and child) provided written informed consent for publication of this report and the accompanying images. A copy of the written consent is available for review by the Editor-in-Chief of this journal.

\section{Consent for publication}

Written informed consent was obtained from the patient's parents for publication of this case report.

\section{Competing interests}

The authors declare that they have no competing interests.

\section{Publisher's Note}

Springer Nature remains neutral with regard to jurisdictional claims in published maps and institutional affiliations.

\section{Author details}

${ }^{1}$ Biotechnology and Biodiversity PhD Program, Federal University of Goias, Rede Centro Oeste de Pós-Graduação de Pesquisa e Inovação, Rua 235, n. 40, Setor Leste Universitário, Goiânia, GO 74605-050, Brazil. ${ }^{2}$ Replicon Research Group, Department of Biology, Pontifical Catholic University of Goias, Rua 235, n. 40, Setor Leste Universitário, Goiânia, GO 74605-050, Brazil. ${ }^{3}$ Genetics Master's Program, Pontifical Catholic University of Goias, Rua 235, n. 40, Setor Leste Universitário, Goiânia, GO 74605-050, Brazil. ${ }^{4}$ Maternity Hospital Amparo, Av T-12 n 280 Setor Bueno, Goiânia, GO, Brazil. ${ }^{5}$ Dr Henrique Santillo Rehabilitation and Readjustment Center, Av. Ver. José Monteiro, 1655, Setor Negrão de Lima, Goiânia, GO, Brazil. ${ }^{6}$ Human Cytogenetics and Molecular Genetics Laboratory, Secretary of Goias State for Public Health, Goiânia, GO, Brazil. 'State University of Goias, Eseffego, Goiânia, Goiás, Brazil.

Received: 23 February 2018 Accepted: 3 September 2018 Published online: 07 September 2018

\section{References}

1. Liehr T, Cirkovic S, Lalic T, et al. Complex small supernumerary marker chromosomes - an update. Mol Cytogenet. 2013;31(6):46-51.

2. Liehr T. Small supernumerary marker chromosomes. 2017. http://ssmc-tl. com/sSMC.html. Accessed 08 Feb 2017.

3. Jafari-Ghahfarokhi H, Moradi-Chaleshtori M, Liehr T, Hashemzadeh-Chaleshtori M, Teimori $\mathrm{H}$, Ghasemi-Dehkordi P. Small supernumerary marker chromosomes and their correlation with specific syndromes. Adv Biomed Res. 2015;27(4):140-6.
4. Jang W, Chae H, Kim J, et al. Identification of small marker chromosomes using microarray comparative genomic hybridization and multicolor fluorescent in situ hybridization. Mol Cytogenet. 2016;8(9):61-70.

5. El Khattabi L, Jaillard S, Andrieux J, et al. Clinical and molecular delineation of Tetrasomy 9p syndrome: report of 12 new cases and literature review. Am J Med Genet A. 2015;167(6):1252-61.

6. Chen CP, Wang LK, Chern SR, et al. Mosaic tetrasomy 9p at amniocentesis: prenatal diagnosis, molecular cytogenetic characterization, and literature review. Taiwan J Obstet Gynecol. 2014;53(1):79-85.

7. Düzcan F, Ergin H, Aytan M, Tepeli E, Özdemir Ö, Basaran S. Non-mosaic Tetrasomy $9 p$ in an infant with multiple congenital anomalies. Gynecol Obstet Reprod Med. 2007;13(2):114-6

8. Ogino W, Takeshima Y, Nishiyama A, Yagi M, Oka N, Matsuo M. Mosaic tetrasomy $9 p$ case with the phenotype mimicking Klinefelter syndrome and hyporesponse of gonadotropin-stimulated testosterone production. Kobe J Med Sci. 2007:53(4):143-50.

9. Di Bartolo DL, El Naggar M, Owen R, et al. Characterization of a complex rearrangement involving duplication and deletion of $9 p$ in an infant with craniofacial dysmorphism and cardiac anomalies. Mol Cytogenet. 2012;5(1):31-6.

10. Verma RS, Babu A. Human chromosomes: Principles and Techiniques. 2nd ed. New York: MacGraw-Hill; 1995.

11. Miller DT, Adam MP, Aradhya S, et al. Consensus statement: chromosomal microarray is a first-tier clinical diagnostic test for individuals with developmental disabilities or congenital anomalies. Am J Hum Genet. 2010;86(5):749-64.

12. Battaglia A, Doccini $V$, Bernardini $L$, et al. Confirmation of chromosomal microarray as a first-tier clinical diagnostic test for individuals with developmental delay, intellectual disability, autism spectrum disorders and dysmorphic features. Eur J Paediatr Neurol. 2013;17(6):589-99.

13. Starke $H$, Nietzel A, Weise A, et al. Small supernumerary marker chromosomes (SMCs): genotype-phenotype correlation and classification. Hum Genet. 2003;114(1):51-67.

14. Pratte-Santos R, Ribeiro KH, Santos TA, Cintra TS. Analysis of chromosomal abnormalities by $\mathrm{CGH}$-array in patients with dysmorphic and intellectual disability with normal karyotype. Einstein (Sao Paulo). 2016;14(1):30-4.

15. Zhou YC, Zhang C, Zhai JS, et al. A patient with unusual features and a 69.5 $\mathrm{Mb}$ duplication from a de novo extra der (9): a case report. Mol Med Rep. 2015;12(1):155-8.

16. Campbell IM, Shaw CA, Stankiewicz P, Lupski JR. Somatic mosaicism: implications for disease and transmission genetics. Trends Genet. 2015;31(7):382-92.

17. Ghymers D, Hermann B, Distèche C, Frederic J. Partial tetrasomy of number 9 chromosome, and mosaicism in a child with multiple malformations (author's transl). Humangenetik. 1973;20(3):273-82.

18. Frémond ML, Gitiaux C, Bonnet D, et al. Mosaic Tetrasomy 9p: a Mendelian condition associated with pediatric-onset overlap myositis. Pediatrics. 2015;136(2):e544-7.

19. Oh M, Cho IJ, Shin S, Lee ST, Choi JR. Isolated $9 p$ duplication with $\operatorname{der}(Y) t(Y$; 9)(q12;p13.2) in a male patient with cardiac defect and mental retardation confirmed by chromosomal microarray. Ann Lab Med. 2016;36(2):191-3.

Ready to submit your research? Choose BMC and benefit from:

- fast, convenient online submission

- thorough peer review by experienced researchers in your field

- rapid publication on acceptance

- support for research data, including large and complex data types

- gold Open Access which fosters wider collaboration and increased citations

- maximum visibility for your research: over $100 \mathrm{M}$ website views per year

At $\mathrm{BMC}$, research is always in progress.

Learn more biomedcentral.com/submissions 